\title{
EDITORIAL
}

\section{Bispectral index in psychiatric patients: Is there a need for a separate monitor?}

The bispectral index (BIS) was conceptualised to provide a substitute for the complex electroencephalograph (EEG) analysis with an easy to understand 'magic' number, to measure hypnotic effect of anaesthetics and sedative drugs. ${ }^{[1]}$ BIS monitoring helps in maintenance of adequate levels of hypnosis and prevents awakening and formation of implicit and explicit memory during general anaesthesia. ${ }^{[2]}$ Intraoperative BIS monitoring has also been found to be useful in fast tracking day-care patients, ${ }^{[3]}$ prevention of postoperative emergence delirium, ${ }^{[4]}$ nausea and vomiting. Since its FDA approval in 1996, BIS monitor usage is extending outside the operating room. Quantitative BIS values correlation has been observed in many neurological conditions like cerebral ischaemia, ${ }^{[5]}$ vasospasm, ${ }^{[6]}$ syncope,${ }^{[7]}$ seizures, ${ }^{[8]}$ cerebral palsy ${ }^{[9]}$ and dementia. ${ }^{[10]}$ It is also found to be useful in predicting efficacy of cardiopulmonary resuscitation, ${ }^{[11]}$ outcome after hypoxic ischaemic injury, ${ }^{[12]}$ and hypoglycaemia, ${ }^{[13]}$ determining effect of hypothermia on the hypnotic state, ${ }^{[14]}$ assessing brain death and level of consciousness in case of brain injury. ${ }^{[15]}$

Although BIS monitoring is being widely used in psychiatric patients during electroconvulsive therapy, its aberrance has still not been evaluated. The present issue of the journal carries an article, in which Ramesh et al., ${ }^{[16]}$ recorded BIS values of patients suffering from psychiatric conditions viz., psychosis, depression, organic and bipolar disorder and compared it with control group patients, who were not suffering from any psychiatric illness. In their study, they observed that BIS values in psychiatric patients are significantly lower compared to the control patients. Patients with psychosis and bipolar disorder were found to have lower BIS values than patients with depression. BIS being an empirical value derived from EEG pattern of approximately 2000 healthy volunteers / patients receiving a variety of commonly used general anaesthetics, sedative-hypnotics and opioids. ${ }^{[1]}$ The question arises whether these values are applicable for psychiatric patients also? Do we need a separate monitor say, BIS ${ }_{p s y}$ derived from

\begin{tabular}{|l|l|}
\hline \multicolumn{2}{|c|}{ Access this article online } \\
\hline Quick Response Code: & Website: \\
\hline & www.jnaccjournal.org \\
\cline { 2 - 2 } & \\
\hline
\end{tabular}

EEG recordings of these patients or a different range of BIS values for them? In an observational study on 18 patients undergoing electroconvulsive therapy (ECT), Gunawardane $e t$ al. found that a low BIS value does not correspond to a deep hypnotic level in patients after ECT. ${ }^{[17]}$

Technological advancements in anaesthesia have brought in monitors which provide continuous display of important variables in a non-invasive manner. These monitors are found to be cost effective, improve safety in perioperative period and have become essential components of our clinical practice. It includes the use of non-invasive blood pressure, pulse oximeter, end-tidal carbon dioxide and BIS. Each one of these monitors provides us with a 'magic number' which guides our intervention(s). However, one must appreciate that these monitors have their own limitations. New devices are known to introduce new informations (and errors!). BIS is no exception. It is known that pulse oximeter, (a reliable monitor displaying oxygen saturation in patients with normal haemoglobin) gives spurious $88 \%$ saturation despite high arterial oxygen saturation in patients with methaemoglobinaemia. On a similar analogy, BIS values (which are derived from normal individuals) might show spuriously low BIS values in psychiatric patients. The study by Ramesh et al. in psychiatric patients observed low BIS values and patients' remain awake with no manifestation of sedation. The key question is whether this BIS value is a true reflection of sedation? Is this low BIS value because of the disease process, because of the psychiatric medications or a combination of these two is a matter which needs further investigation. The study by Ramesh et al. is only the beginning, and there are many more related issues to be studied. Simultaneous correlation of BIS with EEG monitoring, brain imaging and various clinical stages and manifestations of the particular psychiatric illness; choosing similar age group (to remove effect of age related cerebral changes) and numbers in each group, converting into a randomised, controlled trial are some of the ways the quality of such studies can be improved upon. There is a possibility that we might soon have an ideal non- invasive monitor, which can reflect the regression or progression of such illness and help the physicians titrate pharmacotherapy or other modalities of treatment in them. Association of poor outcomes of the patients with low BIS values, in presence or absence of anaesthestic drugs is another area, waiting to be explored. ${ }^{[18]}$ 
Till all these questions are answered, let us only accept that BIS values are low in psychiatric patients and also caution that it might not be a true indicator of the depth of anaesthesia in psychiatric patients.

\section{Rajiv Chawla, Mritunjay Kumar}

Department of Anaesthesiology and Intensive Care, Govind Ballabh Pant Hospital, New Delhi, India Address for correspondence: Dr. Rajiv Chawla, Department of Anaesthesiology and Intensive Care, Govind Ballabh Pant Hospital, University of Delhi, New Delhi - 110 002, India. E-mail: drrajivchawla@gmail.com

\section{REFERENCES}

1. Rampil IJ. A primer for EEG signals processing in anesthesia. Anesthesiology 1998;89:980-1002.

2. Liu J, Harbhej S, White PF. Electroencephalographic bispectral index correlates with intraoperative recall and depth of propofol- induced sedation. Anesth Analg 1997;84:185-9.

3. Liu SS. Effects of bispectral index monitoring on ambulatory anesthesia. A meta-analysis of randomized controlled trials and a cost analysis. Anesthesiology 2004;101:311-5.

4. Berger M, Nadler J, Mathew JP. Preventing delirium after cardiothoracic surgery: Provocative but preliminary evidence for bispectral index monitoring. Anesth Analg 2014;118:706-7.

5. Merat S, Levecque JP, Le Gulluche Y, Diraison Y, Brinquin L, Hoffmann JJ. BIS monitoring may allow the detection of severe cerebral ischemia. Can J Anaesth 2001;48:1066-9.

6. Brallier JW, Deiner SG. Use of the bilateral BIS monitor as an indicator of cerebral vasospasm in ICU patients. Middle East J Anesthesiol 2013;22:161-4.

7. Win NN, Kohase H, Miyamoto T, Umino M. Decreased bispectral index as an indicator of syncope before hypotension and bradycardia in two patients with needle phobia. $\mathrm{Br} \mathrm{J}$ Anaesth 2003;91:749-52.
8. White PF, Rawal S, Recart A, Thornton L, Litle M, Stool L. Can the bispectral index be used to predict seizure time and awakening after electroconvulsive therapy? Anesth Analg 2003;96:1636-9.

9. Choudhry DK, Brenn BR. Bispectral index monitoring: A comparison between normal children and children with quadriplegic cerebral palsy. Anesth Analg 2002;95:1582-5.

10. Renna M, Handy J, Shah A. Low baseline bispectral index of the electroencephalogram in patients with dementia. Anesth Analg 2003;96:1380-5.

11. Lasasso TJ, Muzzi DA, Meyer FB, Sharbrough FW. Electroencephalographic monitoring of cerebral function during asystole and successful cardiopulmonary resuscitation. Anesth Analg 1992;75:1021-4.

12. Myles P, Daly D, Silvers A, Cairo S. Prediction of neurological outcome using bispectral index monitoring in patients with severe ischemic-hypoxic brain injury undergoing emergency surgery. Anesthesiology 2009;110:1106-15.

13. Wu CC, Lin CS, Mok MS. Bispectral index monitoring during hypoglycemic coma. J Clin Anesth 2002;14:305-6.

14. Mathew JP, Weatherwax KJ, East CJ, White WD, Reves JG. Bispectral analysis during cardiopulmonary bypass: The effect of hypothermia on the hypnotic state. J Clin Anesth 2001;13:301-5.

15. Myles PS, Cairo S. Artifact in the bispectral index in a patient with severe ischemic brain injury. Anesth Analg 2004;98:706-7.

16. Ramesh VJ, Radhakrishnan MC, Thimmiah R, Muralidharan K, Thirthali J, Rao GS, et al. Lower Bispectral index values in psychiatric patients: A prospective, observational study. J Neuroanaesthesiol Crit Care 2014;2.

17. Gunawardane PO, Murphy PA, Sleigh JW. Bispectral index monitoring during electroconvulsive therapy. $\mathrm{Br} \mathrm{J}$ Anesth 2002;88:184-7.

18. Leslie K, Short TG. Low bispectral index values and death: The unresolved causality dilemma. Anesth Analg 2011;113:660-3.

How to cite this article: Chawla R, Kumar M. Bispectral index in psychiatric patients: Is there a need for a separate monitor?. J Neuroanaesthesiol Crit Care 2014;1:99-100.

Source of Support: Nil, Conflict of Interest: None declared.

\section{Author Help: Online submission of the manuscripts}

Articles can be submitted online from http://www.journalonweb.com. For online submission, the articles should be prepared in two files (first page file and article file). Images should be submitted separately.

\section{1) First Page File:}

Prepare the title page, covering letter, acknowledgement etc. using a word processor program. All information related to your identity should be included here. Use text/rtt/doc/pdf files. Do not zip the files.

2) Article File:

The main text of the article, beginning with the Abstract to References (including tables) should be in this file. Do not include any information (such as acknowledgement, your names in page headers etc.) in this file. Use text/rtt/doc/pdf files. Do not zip the files. Limit the file size to $1 \mathrm{MB}$. Do not incorporate images in the file. If file size is large, graphs can be submitted separately as images, without their being incorporated in the article file. This will reduce the size of the file.

3) Images:

Submit good quality color images. Each image should be less than 4 MB in size. The size of the image can be reduced by decreasing the actual height and width of the images (keep up to about 6 inches and up to about $1800 \times 1200$ pixels). JPEG is the most suitable file format. The image quality should be good enough to judge the scientific value of the image. For the purpose of printing, always retain a good quality, high resolution image. This high resolution image should be sent to the editorial office at the time of sending a revised article.

4) Legends:

Legends for the figures/images should be included at the end of the article file. 